\title{
"O mínimo do máximo": antítese e estese
}

\author{
Bruna Paola ZERBINATTI (IC - FFLCH - USP)
}

RESUMO: Este trabalho propõe uma leitura do poema "O mínimo do máximo", de Paulo Leminski, tendo em vista a maneira como a questão da apreensão estética exposta por Greimas em Da Imperfeição - aí se apresenta.

PALAVRAS-CHAVE: semiótica; Paulo Leminski; apreensão estética; Algirdas Julien Greimas.

RÉSUMÉ: Ce texte propose une lecture du poème "O mínimo do máximo" de Paulo Leminski, envisageant notamment la façon dont le sujet de la saisie esthétique, exposée par Greimas dans "De l'imperfection”, s'y présente.

MOTS-CLÉS: sémiotique; Paulo Leminski; saisie esthétique; Algirdas Julien

Greimas. 
Em seu último livro individual, Da Imperfeição, publicado em 1987, Greimas trabalha com a noção de estesia. Levando em conta que nossa vida é pautada no cotidiano, esse cotidiano que cria o hábito é dessemantizado; uma "fratura", um inesperado que irrompe traz a essa vida um novo sentido, uma espécie de estado de graça no momento do encontro com o objeto. Temos assim o que se denomina experiência estética.

A propósito dos elementos constitutivos da apreensão estética, em um fragmento do romance Sexta-feira ou Os limbos do Pacífico de Michel Tournier, analisado neste mesmo livro, Greimas aponta "a inserção na cotidianidade, a espera, a ruptura de isotopia, que é uma fratura, a oscilação do sujeito, o estatuto particular do objeto, a relação sensorial entre ambos, a unicidade da experiência, a esperança de uma total conjunção por advir" (2002, p.30). Mais adiante é colocada a idéia da "espera do inesperado" na qual o sujeito fixado em sua cotidianidade seria portador dessa espera de algo extraordinário que traria o deslumbramento, um novo sentido, ainda que sob o risco da própria anulação do sujeito que, na fusão com o objeto, já não encontrará mais sentido para sua busca. Por isso também o momento da apreensão estética não dura muito e, em seguida, o sujeito se vê mais uma vez devolvido a seu estado anterior, munido agora de certa nostalgia, a nostalgia da perfeição.

Podemos ainda verificar que os recentes estudos relacionados ao andamento são de grande valia para nosso propósito visto que, como afirma Zilberberg, "o andamento é senhor, tanto de nossos pensamentos, quanto de nossos afetos, dado que ele controla despoticamente os aumentos e as diminuições constitutivas de nossas vivências." (2006, p.168) Temos, assim, estreitas relações entre o andamento e os elementos da apreensão estética, tanto no que se refere à cotidianidade quanto à própria duração estética. É possível notar que os hábitos do cotidiano trazem uma espécie de lentidão, um andamento que poderia ser considerado lento, enquanto o momento da apreensão estética, no que concerne à duração, é rápido. A respeito disso, citamos mais uma vez Zilberberg (2006, p.171):

" $O$ andamento rege a duração por uma correlação inversa, na medida em que a velocidade, para os homens, abrevia a duração do fazer: Quanto mais elevada é a velocidade, menos longa é a duração - apresentando-se o ser unicamente como um efeito peculiar à lentidão extrema."

Assim, se o ser é um efeito peculiar à lentidão extrema, podemos então observar como se constitui no poema "O mínimo do máximo" de Paulo Leminski, publicado no livro Distraídos Venceremos em 1987: 


\section{O MÍNIMO DO MÁXIMO}

$\begin{array}{rc}1 & \text { Tempo lento, } \\ 2 & \text { espaço rápido, } \\ 3 & \text { quanto mais penso, } \\ 4 & \text { menos capto. } \\ 5 & \text { Se não pego isso } \\ 6 & \text { que me passa no íntimo, } \\ 7 & \text { importa muito? } \\ 8 & \text { Rapto o ritmo. } \\ 9 & \text { Espaçotempo ávido, } \\ 10 & \text { lento espaçodentro, } \\ 11 & \text { quando me aproximo, } \\ 12 & \text { simplesmente me desfaço, } \\ 13 & \text { apenas o mínimo } \\ 14 & \text { em matéria de máximo. }\end{array}$

Tal como em muitos outros poemas do livro, a disposição dos versos no papel não segue um alinhamento à esquerda e as estrofes não são separadas por branco tipográfico. Entretanto, para uma melhor compreensão do poema, podemos dividi-lo em duas partes: uma primeira contendo do verso 1 ao verso 8 ("rapto o ritmo") e outra do nono verso ao décimo quarto. Se considerarmos os 14 versos do poema, há ainda a possibilidade de lê-lo na forma de um soneto, estabelecendo então relações mais justas entre quartetos e tercetos.

O poema constrói-se principalmente através de antíteses e termos colocados de forma antitética - como já é possível notar no título, "o mínimo do máximo". Percebemos, primeiramente, a condição básica de todo sujeito: estar em falta. Temos um sujeito que se vê em falta devido à disjunção de termos colocados como opostos, sendo que a conjunção deles traria uma possível apreensão estética.

A primeira oposição se dá entre Tempo X Espaço e sua duração. Nos primeiros versos, temos:

"Tempo lento,

espaço rápido,

quanto mais penso,

menos capto."

Nestes versos, a oposição entre tempo e espaço é garantida através de parâmetros ligados ao andamento: desaceleração e aceleração se configuram na lentidão do tempo versus a rapidez do espaço. Assim, temos uma oposição Tempo $\mathbf{X}$ Espaço, Lento X Rápido. No plano da expressão é possível notar que a idéia de prolongamento e lentidão é reforçada pela presença de $/ \mathrm{m} / \mathrm{e} / \mathrm{n} /$ nasalizando $/ \mathrm{e} / \mathrm{O}$ 
terceiro verso também se associa ao primeiro na rima de 'penso' com 'lento'. Já no segundo e quarto versos percebemos a recorrência dos fonemas /a/ e /p/ que deixam a idéia da aceleração e certa brusquidão, aceleração esta expressa também no plano do conteúdo pelo verbo 'captar'. De fato, se fizermos a transcrição fonética destes elementos torna-se possível verificar que, além das aliterações utilizadas pelo autor, há certa recorrência vocálica para estabelecer a relação antitética. Temos então:

$\begin{array}{lc}\text { 'tẽjpu } & \text { is'pasu } \\ \text { 'lẽjtu } & \text { 'hapidu } \\ \text { 'pẽjsu } & \text { 'kapitu }\end{array}$

No terceiro e quarto versos aparecem também outros elementos antitéticos: Mais X Menos para opor Pensar X Captar, o que vem a fornecer mais elementos que reforçam o próprio descompasso que se constrói entre aceleração - expresso aqui por 'menos' - e desaceleração - mostrado por 'mais'. Pensando no poema enquanto soneto, estes dois últimos versos estabelecem relações justas com os anteriores encerrando o quarteto e, além do esquema de rimas $\mathrm{ABAB}$ é possível notar certa regularidade métrica: 3/4/4/3 sílabas poéticas. Por fim, esta 'estrofe' que trazia seus versos terminando por vírgula se encerra no último por meio de ponto final.

Poderíamos dizer ainda que esta primeira 'estrofe' faz durar a falta do sujeito, visto que as antíteses não conseguem ser resolvidas. Diante disso, nos versos seguintes o sujeito de estado questiona o valor do objeto através de uma outra antítese entre pegar e o "isso" que lhe passa no íntimo. Denis Bertrand afirma que o valor

"é uma estrutura modal que, afetando uma grandeza semântica qualquer, modifica sua relação existencial com um sujeito. Compreendemos então que o sujeito possui uma existência modal que pode ser perturbada, a todo momento, quer pelas modificações que ele mesmo impõe aos valores dos objetos [...], quer por aquelas que outros atores operam no mesmo ambiente que ele." (2003, p.369)

É como se o estado em que o sujeito se encontra, as diferentes oposições em disjunção anteriormente apresentadas fossem de tal forma irremediáveis que o próprio valor de uma possível conjunção passa a ser discutível. Seguindo as noções de Zilberberg em Razão e poética do Sentido (2006, p.161) de parada e parada da parada para indicar continuidades e descontinuidades, poderíamos dizer que, dentro do quadrado semiótico sugerido, essa apreensão, o 'pegar o isso' corresponderia à chamada parada da continuação, desejada e questionada. 


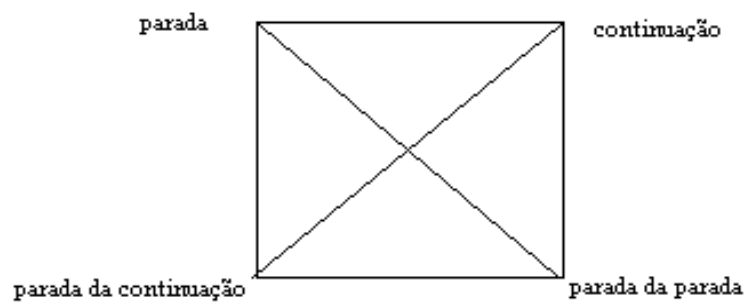

Entretanto, se há o questionamento do valor, o oitavo verso parece solucionar a questão: "rapto o ritmo". Segundo o dicionário Aurélio, ritmo é definido como "num verso ou num poema, a distribuição de sons de modo que estes se repitam a intervalos regulares, ou a espaços sensíveis quanto à duração e à acentuação". Já não se trata mais de captar ou pegar, mas sim raptar nada menos que ritmo, que representa a regularidade entre tempo e espaço lembrando que estes eram então considerados como opostos e insolúveis. Temos no ritmo a conciliação entre tempo e espaço.

Ainda a propósito do ritmo, encontramos no Dicionário de Semiótica (s/d, p. 368) ritmo definido "como uma espera, ou seja, como a temporalização, conseguida mediante a aspectualidade incoativa, da modalidade do querer-ser, aplicada no intervalo recorrente entre agrupamentos de elementos assimétricos, que reproduzem a mesma formação." Verificamos que, mesmo que no ritmo haja a conciliação entre tempo e espaço, ainda assim ela se dá de forma antitética, com o "rapto". Rapto este, que nos remete novamente a uma aceleração.

Se atentarmos mais uma vez para o plano da expressão perceberemos como vai se tecendo a rede de antíteses. Com o rapto do ritmo temos não apenas simples antítese, mas um verdadeiro paradoxo. Se em "rapto" temos a mesma formação vocálica e conteúdo similar de "capto" e "rápido", temos o "ritmo" semelhante ao "íntimo". Entretanto, quando nos deparamos com "rapto o ritmo" temos a sensação de conjunção pelo efeito sonoro provocado não apenas por assonâncias como vinha sendo mostrado mas desta vez por meio de aliteração: ['hapitu] ['hit Simu]

Encontramo-nos diante de uma transformação, de uma parada da continuação que, segundo Da Imperfeição corresponderia a uma fratura, porém neste poema não é possível afirmar que ela está explicitada embora possa ser reconhecida. O rapto do ritmo encerra o que podemos chamar de primeira parte do poema em sua forma peculiar e veremos que de fato os versos que se seguem mostrarão determinadas modificações em relação aos primeiros.

Passando para a denominada "segunda parte" do poema, do verso nove até o fim, ou considerando-os como tercetos, podemos notar a presença de versos mais longos em que o espaço do poema é ocupado por palavras também mais longas e 
aglutinadas. A transformação de estado pela qual passa o sujeito reflete-se também no plano da expressão que se mostra desacelerado.

Os versos nove e dez retomam os elementos do primeiro e segundo, porém em disposição e sentido alterados. No instante imediatamente posterior ao rapto do ritmo o sujeito se depara com um "espaçotempo" que, muito mais que rápido, mostra-se ávido. Ora, Greimas em Da Imperfeição (2002) mostra que na ocorrência da apreensão estética há a suspensão do tempo, fixação do espaço e então o sincretismo entre sujeito e objeto. Poderíamos considerar aqui o que Luiz Tatit, em "A duração estética", chama de duração profunda: "aquela que contém em si os termos polares mas suspende sua manifestação. É a junção que se sobrepõe à disjunção e à conjunção.” (1999, p.203).

Portanto, não nos parece estranho que prossiga a rede de antíteses. O décimo verso, "lento espaçodentro", opõe-se também ao espaçotempo ávido. Outra vez há o aglutinamento de palavras, embora agora haja uma densidade maior no "espaçodentro" que se mostra então lento em oposição ao espaçotempo ávido. É também possível estabelecer um contraste entre o que é mostrado nestes versos e aquilo que ocorria anteriormente; se na primeira parte do poema o espaço era rápido, agora há uma transformação: além de mais denso é lento. O esquema a seguir tenta sistematizar melhor a disposição de tais oposições nos trechos considerados:

\begin{tabular}{|c|c|}
\hline TEMPO & LENTO \\
\hline $\mathrm{X}$ & $\mathrm{X}$ \\
& \\
\hline ESPAÇO & RÁPIDO \\
& \\
\hline
\end{tabular}

Em oposição a:

\begin{tabular}{|c|c|}
\hline ESPAÇOTEMPO & ÁVIDO \\
\hline \multicolumn{2}{|c|}{$\mathrm{X}$} \\
\hline LENTO & ESPAÇODENTRO \\
\hline & \\
\hline
\end{tabular}


Sabe-se também que "a plenitude que todo ser busca não pode durar, sob pena de diluir o sujeito na falta de sentido que ela acarretaria em sua vida" (MOTTA, 2003, p.21) o que vem a explicar tanto a avidez deste tão desejado "espaçotempo" como também os versos 11 e 12 na diluição do sujeito - "quando me aproximo, / simplesmente me desfaço". Alcançando por fim o que desejava, aproximando-se da 'perfeição' a perda de sentido do sujeito é nítida, já não há mais aquela falta de que falávamos no início do poema.

Por fim, os dois últimos versos retomam o título do poema com outra antítese agora entre mínimo e máximo - com o acréscimo de "matéria", construindo assim, junto a "espaço" e "tempo" uma "Física" particular do texto. Tal antítese mostra o momento posterior à apreensão estética, em que o sujeito se encontra de volta ao seu mundo imperfeito com a "nostalgia da perfeição" (GREIMAS, 2002, p.27). Devolvido a seu estágio anterior, faltante porém agora nostálgico sabe o sujeito ser-lhe possível apenas o mínimo do máximo.

\section{REFERÊNCIAS BIBLIOGRÁFICAS}

BERTRAND, Denis. Caminhos da Semiótica Literária. Trad. Grupo Casa. Bauru, SP: EDUSC, 2003.

GREIMAS, Algirdas Julien. Da Imperfeição. São Paulo, Hacker Editores, 2002. \& COURTÉS, Joseph. Dicionário de Semiótica. São Paulo: Cultrix, s/d.

LEMINSKI, Paulo. Distraídos Venceremos. São Paulo: Brasiliense, 1995.

MOTTA, Kary Alessandra. Elementos narrativos e tensivos para abordagem da apreensão estética. Dissertação (Mestrado em Semiótica e Lingüística Geral) USP, São Paulo, 2003.

TATIT, Luiz. "A duração estética”. In: LANDOWSKI, E., DORRA, R. \& OLIVEIRA, A. C. de (eds.) - Semiótica, estesis, estética. São Paulo/Puebla: EDUC/UAP, 1999.

ZILBERBERG, C. Razão e Poética do Sentido. Trad. I. C. Lopes, L. Tatit e W. Beividas. SP: EDUSP, 2006.

2006. . "Síntese da Gramática Tensiva". Significação, 25, Annablume,

\section{Como citar este artigo:}

ZERBINATTI, Bruna Paola. "O mínimo do máximo": antítese e estese. Estudos Semióticos, Número 3, São Paulo, 2007. Disponível em <www.fflch.usp.br/dl/semiotica/es $>$. Acesso em "dia/mês/ano". 